\title{
Host plant selection by the wheat bug Nysius huttoni (Hemiptera: Lygaeidae) on a range of potential trap plant species
}

\author{
S. Tiwari ${ }^{1}$, N. Dickinson ${ }^{2}$, D.J. Saville ${ }^{1}$ and S.D. Wratten ${ }^{1}$ \\ ${ }^{1}$ Bio-Protection Research Centre, Lincoln University, Lincoln 7647, New Zealand \\ ${ }^{2}$ Faculty of Agricultural and Life Sciences, Lincoln University, Lincoln 7647, New Zealand \\ Corresponding author:Sundar.Tiwari@lincolnuni.ac.nz
}

Nysius huttoni is an endemic New Zealand insect pest. Its feeding can seriously reduce crop establishment in forage brassicas. A series of choice, no-choice and paired-choice tests were conducted in a controlledtemperature room to evaluate the pest's host preferences on seedlings of eight plant species: Lobularia maritima (alyssum), Triticum aestivum (wheat), Phacelia tanacetifolia (phacelia), Fagopyrum esculentum (buckwheat), Coriandrum sativum (coriander), Trifolium repens (white clover) and Medicago sativa (alfalfa), and Brassica oleracea (kale) as a potentially susceptible control. In choice tests, wheat was the most preferred followed by alyssum, buckwheat and phacelia, all being significantly more favoured than kale. Survival rate of wheat bugs over 120 h was: on phacelia (71.0\%), clover (69.0\%), alyssum (48.0\%) and wheat (47\%), which were all significantly higher than on kale seedlings. Alyssum and wheat were more susceptible to $N$. huttoni feeding damage than were other tested plants. High survival rates were recorded in paired choice tests on kale and alyssum (78.3\%) compared with the other paired choice tests. The implications of these findings are important for developing ecological management strategies in, or around, forage brassica fields.

\section{Who ate all my leafrollers?}

\author{
J. Poulton ${ }^{1}$, J.T. Todd ${ }^{1}$ and C. McKenna ${ }^{2}$
}

${ }^{1}$ The New Zealand Institute for Plant \& Food Research Limited (PFR), Private Bag 92-169, Auckland

1142, New Zealand

${ }^{2}$ PFR, 412 No. 1 Rd, RD2, Te Puke, New Zealand

Corresponding author: Joanne.Poulton@plantandfood.co.nz

Leafrollers are pests of many fruit crops, and insecticides are used to control their numbers in commercial orchards. However, little is known about how much their natural enemies contribute to their control. Over two summers, larvae of two leafroller species were established in leaf rolls on potted poplar plants, which were placed along shelterbelts in 16 kiwifruit orchards. After a minimum of 38 hours, the leafrollers were retrieved and reared to determine parasitism rates and parasitoid identities. Egg batches and tethered larvae were also placed in the shelterbelts, with some monitored by video cameras, to determine predation rates and predator identities. Up to $3 \%$ of larvae in leaf rolls were parasitised in some orchards, by four different parasitoids, with the fly Trigonospila brevifacies accounting for the majority. Rates of predation were higher, with up to $40 \%$ of eggs, and $37.2 \%$ of larvae being taken. Fourteen different predator taxa were observed feeding on eggs and larvae, with the mite Anystis baccarum, earwigs, and spiders being the primary predators. Understanding which natural enemies are suppressing leafroller populations offers the potential for conserving or increasing those predator and/ or parasitoid numbers in cropping environments. 